\title{
Identification and Characterization of an Inner Ear-Expressed Human Melanoma Inhibitory Activity (MIA)-like Gene (MIAL) with a Frequent Polymorphism That Abolishes Translation
}

\author{
Nanna D. Rendtorff,* Morten Frödin,† Tania Attié-Bitach,‡ Michel Vekemans,‡ \\ and Niels Tommerup*,1
}

\begin{abstract}
* Department of M edical Genetics, Institute of M edical Biochemistry and Genetics, the Panum Institute, University of Copenhagen, 2200 Copenhagen N, Denmark; †Department of Clinical Biochemistry, Glostrup Hospital, 2600 Glostrup, Denmark; and ¥Department of Genetics and INSERM U-393, Hôpital Necker Enfants M alades, Paris, France
\end{abstract}

Received July 5, 2000; accepted October 11, 2000

To discover new cochlea-specific genes as candidate genes for nonsyndromic hearing impairment, we searched in The Institute of Genome Research database for expressed sequence tags isolated from the cochlea only. This led to the cloning and characterization of a human gene named melanoma inhibitory activity-like (MIAL; HGMW-approved symbol OTOR alias MIAL) gene. In situ hybridization revealed MIAL expression in a cell layer beneath the sensory epithelium of cochlea and vestibule of human fetal inner ear. No other human tissue, except fetal brain, showed expression of MIAL when analyzed by in situ hybridization or reverse transcription-polymerase chain reaction. The cDNA of the mouse homologue was also cloned and mapped about $80 \mathrm{cM}$ from the top of mouse chromosome 2. In mouse, Mial was also expressed in the cochlea and the vestibule of the inner ear, as well as in brain, eye, limb, and ovary. Expression in mammalian cell cultures showed that MIAL is translated as an $\sim 15-\mathrm{kDa}$ polypeptide that is assembled into a covalently linked homodimer, modified by sulfation, and secreted from the cells via the Golgi apparatus. In the human MIAL gene, a frequent polymorphism was discovered in the translation initiation codon (ACG instead of ATG). Of 505 individuals, 48 (9.5\%) were ATG/ ACG heterozygous and $1(0.2 \%)$ was homozygous for ACG. No MIAL protein was synthesized in cells transfected with CDNA of the ACG allele. The inner earrestricted expression pattern and the existence of an inactive allele suggest that MIAL may contribute to inner-ear dysfunction in humans. ๑ 2001 Academic Press

Sequence data from this article have been deposited with the EMBL/GenBank Data Libraries under Accession Nos. AJ 242552 (human gene) and AJ 243939 (mouse cDNA).

${ }^{1}$ To whom correspondence should be addressed at Department of Medical Genetics, Institute of Medical Biochemistry and Genetics, the Panum Institute, University of Copenhagen, Blegdamsvej 3, DK-2200 Copenhagen N, Denmark. Telephone: +45 35327826. Fax: +45 35327845. E-mail: tommerup@imbg.ku.dk.

\section{INTRODUCTION}

Genetic hearing loss is referred to as nonsyndromic if no other anomalies are associated with the hearing impairment. N onsyndromic deafness is one of the most heterogeneous hereditary conditions (reviewed in Petit, 1996; Keats and Berlin, 1999; Steel, 2000). More than 60 different chromosomal loci for non-syndromic deafness have been reported, but only 15 of the corresponding genes have been identified (Van Camp and Smith, 2000). Most of these deafness genes are required for the function of the cochlea, which is the auditory sense organ of the inner ear. Genes specifically expressed in the cochlea are therefore candidates for unidentified nonsyndromic deafness genes. To discover new cochlea-specific genes, we searched the Human Gene Index ( $\mathrm{HGI}$ ) database at The Institute of Genome Research (TIGR), using a search query that is able to identify expressed sequence tags (ESTS) of CDNAs that have been isolated from one tissue only, in our case from the cochlea. This led to the cloning of a gene that is related to the melanoma inhibitory activity (MIA) gene and therefore named MIA-like (MIAL). ${ }^{2}$

MIA is an extracellular matrix protein that was isolated based on its ability to inhibit melanoma cell growth in vitro (Blesch et al., 1994). MIA is translated as a 131-amino-acid precursor with a signal peptide. The mature secreted protein is composed of 107 amino acids. Homologues with more than $85 \%$ amino acid identity have been identified in mouse, rat, and cow (Bosserhoff et al., 1997c; Dietz and Sandell, 1996). MI A is highly and broadly expressed by chondrocytes during fetal chondrogenesis and in adult cartilaginous tissues, and it is believed to function as a regulatory molecule in cartilage formation (Bosserhoff et al., 1997c; Dietz and Sandell, 1996; Neame et al., 1999). Therefore, MIA is also known as cartilage-derived reti-

\footnotetext{
${ }^{2}$ The HGMW-approved symbol for the gene described in this paper is OTOR alias MIAL.
} 
noic acid-sensitive protein (CD-RAP) (Dietz and Sandell, 1996). In addition, MIA is synthesized by preosteoblasts during tooth healing (Shyng et al., 1999). Virtually all primary and metastatic melanoma cells, but not normal melanocytes, express and secrete MIA to a high extent, such that MIA serum levels serve as a marker for malignant melanoma (Bosserhoff et al., 1997b, a; Deichmann et al., 1999). Neoplastic expression of MIA has also been observed in mammacarcinoma (Bosserhoff et al., 1999b), ovarian cancer (Bosserhoff et al., 1999a), and various gastrointestinal carcinomas (Wagner et al., 2000). Although MIA is thought to play an important role in cartilage formation, the cellular actions of MIA are not clear. I ncubation of cultured melanoma cells or chondrocytes with recombinant MIA protein leads to rapid cell rounding and inhibition of cell growth (Blesch et al., 1994; Kondo et al., 1998). Furthermore, MIA has been shown to interact with fibronectin and Iaminin, possibly via the binding motif for integrins in these molecules, and to inhibit the attachment of suspended melanoma cells to culture surface coated with laminin or fibronectin (Bosserhoff et al., 1997a, 1998). In cartilage, MIA protein is localized to cell bodies of chondrocytes and their immediate vicinity and does not seem to be a constituent of cartilage matrix (Bosserhoff et al., 1997c). Based on these observations, it has been proposed that one function of MIA is to regulate (restrict) cell-matrix interactions, possibly by masking binding sites in laminin and fibronectin for integrins on the cell surface (Bosserhoff et al., 1998). In neoplastic cells, expression of MIA may therefore lead to enhanced metastatic potential.

Here, we report on a human gene and its mouse CDNA homologue that are related to MI A and therefore named MIA-like (MIAL). We have characterized MIAL gene structure, mRNA distribution, subcellular protein localization, posttranslational modification, and secretion. Our results suggest that MIAL encodes a small extracellular protein that is preferentially expressed in the inner ear in human. We also report a frequent polymorphism in the initiation codon of human MIAL that abolishes synthesis of MIAL protein, suggesting that MIAL may be involved in human inner-ear dysfunction.

\section{MATERIALS AND METHODS}

Database searches and sequence analysis. The cochlea-specific EST cluster, tentative human consensus (THC) sequence 147247, was retrieved from TIGR $\mathrm{HGI}$ (http://www.tigr.org/tdb/hgi/searching/ hgi_xpress_search.html), which lists contigs of ESTs and organizes these clusters according to tissue expression. Nucleic acid homology searches and protein sequence comparisons were carried out using BLAST (http://www.ncbi.nlm.nih.gov/BLAST). Sequence alignments were performed using the ClustalW multiple sequence alignment algorithm (http://dot.imgen.bcm.tmc.edu:9331/multi-align/multi-align. html). The NIX program at the Human Genome Mapping Project Resource Center (HGMP-RC) (http://www.hgmp.mrc.ac.uk/homepage. html) was used to define the positions of potential coding sequences. Sequencing of polymerase chain reaction (PCR) products was per- formed manually with ${ }^{32} \mathrm{P}$-end-labeled primers or by incorporation of ${ }^{33} \mathrm{P}$-labeled dideoxy nucleotides (Amersham Pharmacia Biotech) using the Thermo Sequenase cycle sequencing kit (Amersham Pharmacia Biotech). Sequencing of plasmid DNA was performed on an ALFexpress DNA sequencer (Amersham Pharmacia Biotech). Prediction of the secretory signal peptide and cleavage site was performed using the SignalP program version 2.0 (http://www.cbs.dtu.dk/services/SignalP/). Hydrophilicity plots were constructed by Kyte-Doolittle analysis (http://bioinformatics.weizmann.ac.il/hydroph/). Prediction of O-glycosylation and binding sites for transcription factors was carried out with the NetOGlyc 2.0 program (http://www.cbs.dtu.dk/services/NetOGlyc/) and MOTIF (http://www.motif.genome.ad.jp/), respectively.

Polymerase chain reaction conditions. PCR was performed in $15-\mu l$ reactions containing 10 pmol primer, $10 \mathrm{mM}$ Tris- $\mathrm{HCl}, \mathrm{pH} 8.3$, $50 \mathrm{mM} \mathrm{KCl}, 1.5 \mathrm{mM} \mathrm{MgCl}_{2}, 0.001 \%(\mathrm{w} / \mathrm{v})$ gelatin, a $0.17 \mathrm{mM}$ concentration of each dNTP, $3 \mathrm{mM}$ cresol red, 12\% sucrose, and $0.5 \mathrm{U}$ AmpliTaq polymerase (Boehringer Mannheim). PCR amplifications were performed in a PTC-225 DNA engine (MJ Research).

CDNA cloning of human and mouse MIAL. Human MIAL CDNA was isolated from fetal whole brain total RNA (Clontech Catalog No. 64019-1) by reverse transcription (RT) and PCR using the $5^{\prime}$ primer (5'-AAAGGCAGGAACCACTGAAGTC-3') and the $3^{\prime}$ primer (5'AGCTCAACATTTCCCCGCTCTA-3'). The PCR product was cloned into the pPCR-Script Amp vector (Stratagene) and sequenced on both strands. The $3^{\prime}$ end of MIAL CDNA was obtained by sequencing of I MAGE Clone 285357, GenBank Accession No. N63222 (contained in THC 147247), purchased from HGMP-RC. To isolate murine Mial cDNA, the mouse IMAGE Clone 661055 (GenBank Accession No. AA222797), showing homology to the human MIAL 3' coding region, was purchased from HGMP-RC and sequenced on both strands. To obtain the $5^{\prime}$ end of the mouse transcript, total RNA was prepared from embryonic day (E) 12.5 whole mouse and 5'-RACE was performed using the SMART RACE CDNA Amplification Kit (Clontech Catalog No. K 1811-1) with a gene-specific primer (complementary to nucleotides 305 to 332 of GenBank Accession No. AA222797). The reconstructed open reading frame of mouse $\mathrm{Mial}$ was verified by RT-PCR performed on E 12.5 whole mouse RNA using the primers mMial-v1F (5'-CAGCAAGAAGGAAGATGGCAAG-3') and mMialv1R (5'-GTCAGAGCTGGGGAGAATGACC-3') annealing in the 5'and $3^{\prime}$-untranslated region (UTR), respectively. The PCR product was cloned and sequenced.

Radiation hybrid mapping of mouse Mial. The T31 mouse radiation hybrid mapping panel consisting of DNA from 100 hybrids was obtained from Research Genetics (http://www.resgen.com/). Fifty nanograms of DNA from each hybrid cell line was screened twice for the presence or absence of the Mial gene using the PCR primers mMial-clF (5'-CAGATAAAACAGAAACACCAGT-3') and mMialclR (5'-GGGGCAAGAGTAAACAAGA-3') designed to amplify a 158-bp fragment of the Mial-3' UTR. Standard PCR amplification was performed using an annealing temperature of $52^{\circ} \mathrm{C}$. Genotype data for the 100 clones were sent to The J ackson Laboratory (http:// www.jax.org/resources/documents/cmdata/rhmap/rhsubmit.html) to determine the chromosomal location of Mial with respect to the Mouse Genome Database (MGD) linkage map (http://www. informatics.jax.org/).

In situ hybridization. Human conceptuses were collected from legally terminated pregnancies in agreement with the French law and Ethics Committee recommendations. Tissues were fixed with $4 \%$ paraformaldehyde, embedded in paraffin blocks, and sectioned at 5 $\mu \mathrm{m}$. A 688-bp PCR product of MIAL CDNA (corresponding to bp -69 to +619 ) was cloned into a pPCR-Script Amp vector (Stratagene). The PCR product (688 bp) shows $<50 \%$ homology with MIA CDNA and thus is likely to hybridize specifically to MIAL mRNA. Sense and antisense riboprobes were generated using either T3 or T7 RNA polymerase in the presence of $\alpha^{-{ }^{35}} \mathrm{~S}-U T P(1200 \mathrm{Ci} / \mathrm{mmol} ; \mathrm{NEN})$. Labeled probes were purified on Sephadex G50 columns. Hybridization and posthybridization washes were carried out according to Wilkinson (1992). Slides were dehydrated, exposed to Biomax MR X-ray films (Amersham Pharmacia Biotech) for 3 days, dipped in 
Kodak NTB2 emulsion for 17 days at $+4^{\circ} \mathrm{C}$, developed, counterstained with toluidine blue, and coverslipped with Eukitt. No hybridization signal was detected with the $\alpha{ }^{-35} \mathrm{~S}$-labeled sense probe, confirming that the in situ hybridization pattern of the $\alpha^{-}{ }^{35} \mathrm{~S}$-labeled antisense probe was specific.

Laser capture microdissection. Heads of E17 mouse and 8- to 10-week-old human fetuses, obtained after permission was granted by the Danish Scientific Ethical Committee, were frozen in TissueTek embedding medium OCT (Miles), sectioned at 8-10 $\mu \mathrm{m}$ in a cryostat, mounted on uncoated microscope glass slides, and stored at $-80^{\circ} \mathrm{C}$. Frozen tissues sections were fixed in $70 \%$ ethanol and stained with hematoxylin and eosin. Thereafter sections were dehydrated in alcohol and then in xylene and air-dried. Using the PixCell II Laser Capture Microdissection System (Arcturus Engineering Inc.), cells were microdissected according to the manufacturer's protocol. Total RNA was extracted from the cells using the Micro RNA isolation kit (Stratagene). Reverse transcription was performed essentially as described below.

RNA isolation and RT-PCR analysis. Total RNA was prepared (Chomczynski and Sacchi, 1987) from snap-frozen tissues from human embryos and fetuses ranging from 6 to 12 weeks of development or from embryonic (E 14.5), postnatal, and adult mouse. Human total RNA from adult tissues and fetal brain was obtained from Clontech. RNA was treated with RNase-free DNase I (Gibco BRL), and CDNA was synthesized using oligo(dT) ${ }_{11} \mathrm{~V}$ primers and Superscript II (Gibco BRL). CDNA, synthesized from approximately 20 ng RNA, was amplified by PCR with primers to MIAL, MIA, or $\beta$-ACTIN CDNA. CDNA derived from 30 metastatic melanoma cell lines was prepared as described (Guldberg et al., 1997). For human MIAL and MIA, two independent primer sets were used and found to give similar results. One set was designed to amplify sequence across exon-intron borders to exclude amplification of genomic DNA. Primer sequences were as follows: hMIAL-7F, 5'-TCCTCTTTTATCTGCCACCTCC-3'; hMIAL-7R, 5'-GAGATGGGAGTCGTGGGTTATT-3'; hMIAL-THCF , 5'-ATGCATCCCCCTGTAAGAG-3'; hMIALTHCR, 5'-GGTTGGAGGTGGCAGATA-3'; hMIA-v1F, 5'-CCAAGTGGTGTATGTCTTCTCCAA-3'; hMIA-v1R, 5'-GGCAGTAGAAATCCCATTTGTCTGT-3'; hMIA-r2F, 5'-TGTGTGCGGACCAGGAGTG; hMIA-r2R, 5'-GAAATAGCCCAGGCGAGCAG-3'; mMial-m3F, 5'CCCAGCAACTTGGTGAAGGAGCAGCGT-3'; mMial-m3R, 5'-CAGTTGGTGGAAAGACCGGGGCAAGAG-3'; mMia-1F， 5'-GCAGTGTTCAGGGAGGTTA-3'; mMia-1R, 5'-TGCAGGGATAGCGGTAG-3'; $\beta$-ACTINA, 5'-AAGTGTGACGTTGACATCCG-3'; and $\beta$-ACTINB, 5'GATCCACATCTGCTGGAAGG-3'.

MIAL expression vectors. To generate myc-tagged MIAL expression vector, CDNA of human MIAL or the ACG initiation codon MIAL variant was amplified by PCR using a sense primer complementary to nucleotides -68 to -41 from the initiation codon and introducing a Xhol site (5'-CACGCTCGAGAAGGCAGGAACCACTGAAGTCAGTCCC $-3^{\prime}$ ) and an antisense primer deleting the natural stop codon and introducing a Notl site (5'-CCATAGCGGCCGCCTCGCAGAAGAAGTCAATATCCGTG-3'). To generate myc-MIAL $23-128$, the sense primer used annealed at the second in-frame ATG codon at nucleotides 67 to 87 and a Kozak consensus sequence and a Xhol site were introduced upstream thereof (5'-CACGCTCGAGACCATGGACCGTCTAGCTTCCAAG-3'). PCR products were digested with Xhol and Notl, and iserted in-frame with a C-terminally located 9-amino-acid myc epitope tag in the mammalian expression vector pE F (pEF/myc/cyto) (Invitrogen). To generate MIAL tagged with the 9-amino-acid hemagglutinin (HA) epitope, cDNA of human MIAL was amplified by PCR using a sense primer complementary to nucleotides -68 to -47 from the initiation codon and introducing a Notl site (5'-CAGTCGATAGCGGCCGCAAGGCAGGAACCACTGAAGTC-3') and an antisense primer deleting the natural stop codon and introducing a Notl site (5'-GACACGTAGGCGGCCGCCTCGCAGAAGAAGTCAATATC-3'). The PCR product was digested with $\mathrm{N}$ otl and inserted in-frame with a C-terminally located HA tag in the mammalian expression vector pMT2 (Grove et al., 1993) using the Notl site. Before subcloning, the pMT2 vector had been modified by excision of the RSK 1 gene present in the vector and introduction of a stop codon after the HA tag. All plasmid inserts were checked for PCR-introduced errors by sequencing.

Expression of MIAL in cultured cells. COS7 cells were cultured in Dulbecco's modified Eagle's medium supplemented with $10 \%$ fetal bovine serum at $37^{\circ} \mathrm{C}$ in atmospheric air containing $5 \% \mathrm{CO}_{2}$. For transfection, monolayers of $\sim 3.2 \times 10^{5}$ cells in 9.6- $\mathrm{cm}^{2}$ dishes were incubated for $4 \mathrm{~h}$ in serum-free medium with $1.5 \mu \mathrm{g}$ DNA complexed with $12 \mu \mathrm{l}$ of LipofectAMINE (Life Technologies, Inc.) according to the manufacturer's instructions. After transfection, the medium was replaced with medium containing $10 \%$ fetal bovine serum, and cells were cultured for 24 or $48 \mathrm{~h}$. To analyze secretion of myc-tagged MIAL, cells were washed three times with serum-free medium and incubated for 10 or $18 \mathrm{~h}$ in serum-free medium supplemented with 30 nM insulin-like growth factor II to promote cell survival. Thereafter, the medium was collected, and cells were washed with phosphatebuffered saline solution (PBS), pH 7.4, and lysed in SDS-PAGE sample buffer ( $2 \%$ sodium dodecyl sulfate, $62 \mathrm{mM}$ Tris ( $\mathrm{pH} 6.8$ ), 10\% glycerol, $5 \% \beta$-mercaptoethanol, 0.1\% (w/v) bromphenol blue). MIAL in the medium was isolated by immunopurification. Briefly, the medium was centrifuged for $3 \mathrm{~min}$ at $1000 \mathrm{~g}$ to remove contaminating cells, and the supernatant was subsequently centrifuged for $10 \mathrm{~min}$ at $20,000 \mathrm{~g}$ to remove the remaining debris. The supernatant was incubated with $2 \mu \mathrm{g}$ monoclonal mouse anti-myc 9E 10 antibody (Santa Cruz Biotechnologies) for $2 \mathrm{~h}$ at room temperature with the addition of $25 \mu \mathrm{l}$ of a $50 \%$ slurry of protein G-agarose beads (Amersham Pharmacia Biotech) during the final 45 min. Agarose beadsantibody complexes were precipitated by centrifugation, washed five times with $0.5 \%$ Triton X-100, $150 \mathrm{mM} \mathrm{NaCl}, 10 \%$ glycerol, $50 \mathrm{mM}$ Tris- $\mathrm{HCl}(\mathrm{pH}$ 7.4), drained, and dissolved in SDS-PAGE sample buffer.

Coimmunoprecipitation of HA-MIAL and myc-MIAL. COS7 cells were cotransfected with $0.75 \mu \mathrm{g}$ plasmid expressing myc-MIAL and HA-MIAL or empty HA vector. After $48 \mathrm{~h}$, cells were washed with PBS and then solubilized for $15 \mathrm{~min}$ in $500 \mu \mathrm{l}$ lysis buffer $(0.5 \%$ Triton X-100, $150 \mathrm{mM} \mathrm{NaCl}, 50 \mathrm{mM}$ Tris- $\mathrm{HCl}$ (pH 7.4), 10\% glycerol, $5 \mathrm{mM}$ EDTA, $25 \mathrm{mM} \mathrm{NaF}, 1 \mathrm{mM}$ phenylmethylsulfonyl fluoride, 10 $\mu \mathrm{M}$ leupeptin, $10 \mu \mathrm{M}$ pepstatin, and 200 kallikrein inhibitor units/ml aprotinin) on ice. Subsequent manipulations were performed at $0-4^{\circ} \mathrm{C}$. Cell extracts were clarified by centrifugation for 10 min at $14,000 \mathrm{~g}$, and the supernatant was incubated with $2 \mu \mathrm{g}$ mouse monoclonal 12CA5 anti-HA antibody for $2 \mathrm{~h}$ with the addition of 20 $\mu \mathrm{l}$ of a $50 \%$ slurry of protein A-agarose beads (Amersham Pharmacia Biotech) during the final $25 \mathrm{~min}$. Agarose beads-antibody complexes were precipitated by centrifugation, washed five times with Iysis buffer, drained, and dissolved in SDS-PAGE sample buffer.

Immunoblotting. Protein samples were fractionated by $15 \%$ SDS-PAGE and electroblotted onto Hybond polyvinylidene difluoride membrane (Amersham Pharmacia Biotech). Membranes were blocked overnight with 5\% (w/v) nonfat dry milk (Carrefour, Paris, France) in Tris-buffered saline ( $\mathrm{pH}$ 7.6) and incubated with $9 \mathrm{E} 10$ antibody to the myc tag or with rabbit polyclonal antibody to the HA tag (Santa Cruz Biotechnologies). The primary antibodies were visualized by incubation with anti-mouse or anti-rabbit antibody coupled to horseradish peroxidase followed by enhanced chemiluminescence development (Amersham Pharmacia Biotech) and autoluminography.

Metabolic ${ }^{35}$ S-labeling. Monolayers of $\sim 2 \times 10^{6}$ COS7 cells in $57-\mathrm{cm}^{2}$ dishes were transfected with plasmid expressing myc-tagged MIAL and cultured for $48 \mathrm{~h}$. Cells were then washed twice with PBS and incubated with sulfate and serum-free minimum essential Eagle's medium supplemented with $15 \mathrm{mM}$ Hepes (pH 7.4), $5 \mathrm{nM}$ insulin-like growth factor $\mathrm{II}$, and $0.5 \mathrm{mCi} / \mathrm{ml}$ sodium $\left[{ }^{35} \mathrm{~S}\right]$ sulfate. After $18 \mathrm{~h}$, the medium was collected, centrifuged for $3 \mathrm{~min}$ at $1000 \mathrm{~g}$, and centrifuged thereafter for $10 \mathrm{~min}$ at 20,000g. The supernatant was precleared by incubation with protein G-agarose for $20 \mathrm{~min}$. Thereafter, agarose beads were removed by centrifugation, and MIAL was precipitated from the supernatant as described above. 
Immunocytochemistry. Transfected COS7 cells grown on glass coverslips coated with poly-D-Iysine were washed with PBS, fixed with 4\% paraformaldehyde in PBS for $10 \mathrm{~min}$, permeabilized with $0.2 \%$ Triton X-100 in PBS, and incubated for 20 min with $10 \%$ horse serum in PBS. Cells were then incubated for $1 \mathrm{~h}$ with mouse antiGolgi 58K antibody (Sigma) (10 $\mu \mathrm{g} / \mathrm{ml})$ and rabbit anti-myc antibody $(0.5 \mu \mathrm{g} / \mathrm{ml})$ (Santa Cruz Biotechnologies) in PBS containing $2 \%$ horse serum. Cells were rinsed five times with PBS and incubated for 45 min with Texas red-conjugated anti-mouse antibody $(5 \mu \mathrm{g} / \mathrm{ml})$ and fluorescein-isothiocyanate (FITC)-conjugated anti-rabbit antibody (2 $\mu \mathrm{g} / \mathrm{ml}$ ) (both from J ackson Immunochemicals). In this double-immunostaining protocol, no cross-reaction was observed between secondary antibody and the inappropriate primary antibody or the horse serum (data not shown). After being washed, the coverslips were mounted on slides. Cells were examined with a Leica DMRB epifluorescence microscope with the appropriate filters, and images were captured using a Sensys 1400 CCD camera (Photometrics) and IPLab Spectrum imaging software (Vysis).

Analysis of initiation codon polymorphism in human MIAL. A 254-bp PCR product containing the initiation codon of MIAL was PCR-amplified from genomic DNA extracted from whole blood of unrelated individuals using standard methods. PCR was carried out in $15 \mu \mathrm{l}$ using the primers hMIAL-9F (5'-CATCTGCACAGAGCTTCTTGGA-3') and hMIAL-9R (5'-GAGCAGCCTGTTATGAAAACGG-3'). Thermocycler conditions were an initial denaturation at $95^{\circ} \mathrm{C}$ for $3 \mathrm{~min}$; $32 \mathrm{cycles}$ of $94^{\circ} \mathrm{C}$ for $15 \mathrm{~s}, 54^{\circ} \mathrm{C}$ for $20 \mathrm{~s}$, and $72^{\circ} \mathrm{C}$ for $30 \mathrm{~s}$; with a final extension for $5 \mathrm{~min}$ at $72^{\circ} \mathrm{C}$. Seven microliters of the PCR sample was digested overnight with $5 \mathrm{U}$ Bbsl (New England Biolabs) in a $40-\mu$ l reaction and analyzed on $2 \%$ agarose gels.

\section{RESULTS}

\section{Cloning of Human and Mouse MIAL CDNA}

In a search for cochlea-specific EST clusters using the TIGR HGI database, we retrieved THC 147247, which is assembled from four ESTs originating from a human cochlear cDNA library (Robertson et al., 1994). By database searching, we found a human genomic clone, 705D16 (GenBank Accession No. AL034428), from chromosome 20 that showed $100 \%$ identity to the 390 nucleotides of THC 147247. Integrated genomic sequence analysis using the NIX program predicted four exons in clone 705D16 immediately upstream from the sequence with homology to THC 147247. The predicted exons encoded a protein with significant homology to MIA. To clone the CDNA of the MIA homologue, RT-PCR was performed using primers based on sequence upstream of the predicted exon 1 (upstream primer) and THC 147247 (downstream primer). cDNA from human whole fetal brain, which may contain tissue of inner-ear origin, as discussed below, was used as template. The PCR resulted in a 688-bp product. The contig of this PCR product and THC 147247 is shown in Fig. 1A. The longest open reading frame predicts a 128-amino-acid protein of $14.3 \mathrm{kDa}$, in which the first 20 amino acids constitute a potential signal peptide with a likely cleavage site between residues 20 and 21 . Overall, this protein shows $45 \%$ identity and $63 \%$ similarity to MIA (Fig. 1B), but no significant similarity to any other sequence in the databases. Due to the homology with MIA, the protein was named MIAL for MIA-like. The 5'-UTR of MIAL MRNA has not been precisely determined, but by RT-PCR we could amplify
MIAL CDNA with a $5^{\prime}$ primer corresponding to bp -83 to -60 . Thus, the $5^{\prime}$ end extends at least 83 nucleotides upstream from the predicted translation initiation codon. The sequence around the initiation codon conforms to a Kozak consensus sequence (GCCACCatgG) with respect to the most important nucleotides, i.e., a purine at -3 and a guanine at +4 (Kozak, 1996). This translation initiation site is preceded by an in-frame stop codon located 51 nucleotides upstream. The MIAL mRNA appears to be subject to alternative polyadenylation. Thus, six cochlear EST s exist in GenBank with a poly $(A)$ tail 468 nucleotides downstream from the stop codon and 14 nucleotides downstream from a canonical AATAAA polyadenylation signal (Fig. IA). In addition, three cochlear ESTs (GenBank Accession Nos. H87930, H88326, and N67179) suggest polyadenylation 1045 nucleotides downstream from the stop codon and 24 nucleotides downstream from an ATTAAA polyadenylation signal. Finally, one cochlear EST (GenBank Accession No. H89184) suggests that MIAL mRNAs with a 3'-UTR longer than 1316 nucleotides may exist, but no canonical polyadenylation signal or a $\operatorname{poly}(A)$ tail was present in this EST sequence.

We next cloned the murine homologue of MIAL. The $3^{\prime}$ coding region of human MIAL showed homology to an EST (GenBank Accession No. AA222797) originating from an embryonic whole mouse cDNA library. Sequencing of the EST clone revealed that it encoded the final 45 amino acids only of the putative murine homologue of MIAL. Therefore 5'-RACE-PCR was performed on E12.5 whole mouse RNA, which yielded a single PCR product of about $650 \mathrm{bp}$. The CDNA contig of the 5'-RACE-PCR product and the insert of I MAGE Clone 661055 contained an open reading frame predicting a 128-amino-acid protein with a putative 18-aminoacid secretory signal peptide with a likely cleavage site between residues 18 and 19. Thus, the predicted preprotein is the same size as human $\mathrm{MIAL}$, and the two proteins show an overall amino acid identity of $87 \%$ and a similarity of $92 \%$ (Fig. 1C). The sequence surrounding the start ATG of the mouse CDNA is identical to that of human MIAL and thus contains a Kozak sequence with the two most important positions conserved. We therefore conclude that the cDNA represents the murine homologue of human $M I A L$, and we have named the mouse gene Mial. The 5'-UTR of Mial extends at least 23 nucleotides upstream of the putative initiation methionine as indicated by $5^{\prime}$-RACE. The insert of I MAGE Clone 661055 shows a 535-nucleotide $3^{\prime}$-UTR of mouse Mial. Nineteen nucleotides upstream of the poly $(A)$ tail, a CATAAA sequence is located that directs polyadenylation with $20 \%$ efficiency compared with the canonical AATAAA sequence (Wickens, 1990).

MIA contains four cysteine residues thought to be important for the tertiary structure (Blesch et al., 1994). These four cysteines are conserved in human and mouse MIAL. Moreover, hydropathic analysis of the MIA and MIAL family of proteins using Kyte- 
A

1 AAAGGCAGGAACCACTGAAGTCAGTCCCCGCTTCCAGTCAGAGTTCAAGTTAAAACAGAAAAAAGGAAGATGGCAAGAATATTGTTACTT

91 TTCCTCCCGGGTCTTGTGGCTGTATGTGCTGTGCATGGAATATTTATGGACCGTCTAGCTTCCAAGAAGCTCTGTGCAGATGATGAGTGT

181 GTCTATACTATTTCTCTGGCTAGTGCTCAAGAAGATTATAATGCCCCGGACTGTAGATTCATTAACGTTAAAAAAGGGCAGCAGATCTAT $\begin{array}{lllllllllllllllllllllllllllllllll}V & Y & \text { T } & I & S & L & A & S & A & Q & E & D & Y & N & A & P & D & C & R & F & I & N & V & K & K & G & Q & Q & I & Y\end{array}$

271 GTGTACTCAAAGCTGGTAAAAGAAAATGGAGCTGGAGAATTTTGGGCTGGCAGTGTTTATGGTGATGGCCAGGACGAGATGGGAGTCGTG $\begin{array}{lllllllllllllllllllllllllllllllll}V & Y & S & K & \text { L } & \text { V } & \text { K } & \text { E } & \text { N } & G & A & G & E & \text { F } & \text { W } & \text { A } & G & \text { S } & \text { V } & \text { Y } & G & D & G & \text { Q } & \text { D } & \text { E } & \text { M } & G & \text { V } & \text { V }\end{array}$

361 GGTTATTTCCCCAGGAACTTGGTCAAGGAACAGCGTGTGTACCAGGAAGCTACCAAGGAAGTTCCCACCACGGATATTGACTTCTTCTGC $\begin{array}{llllllllllllllllllllllllllllllllll}G & Y & F & P & R & N & L & V & K & E & Q & R & V & Y & Q & E & A & T & K & E & V & P & T & T & D & I & D & F & F & C\end{array}$

451 GAGTAATAAATTAGTTAAAACTGCAAATAGAAAGAAAACACCAAAAATAAAGAAAAGAGCAAAAGTGGCCAAAAAATGCATGTCTGTAAT $\mathrm{E}$ *

541 TTTG 3 ACTGACGTTTTAAGAATTTGTTACCTTACAGAAGAGCAAGGGCTTAGGGGTTGGAGGTGGCAGATAAAAGAGGATTTTCAACTCA 631 AATCTTGTTTCCTGCTGGCCTGGTCTGCCCACGAGCTAGAGCGGGGAAATGTTGAGCTCAAATGGGTAAATTGAGACCAGAAAATTATTT 721 TTTCAACCTAGAGAATCTCCTCTTACAGGGGGATGCATATAACAGATCATGTATGTGTAGTTATTTCTAAGTAGTAATTCTTCCCAGCTC

811 TTTGATTTGCCATATATAAAATAGGTGGGTCGTATGTCTTCCCTTTAGACATGATGTTTTCTACTCATTTGTCTCTCTGGCCAATTGAAT

901 TATTAATAAAAGGTCTGTATTATCAAAAAAAAAAAAAAA

B

$\begin{array}{llll}\text { hMIAL } & 1 \text { MAR----TLLIFLPGLVAVAVHGIFMDRLASKKLCADDECVYTISTASAOEDYNAPDCR } \\ \text { hMIA } & 1 \text { MARSLVCLGVIILLSAFSGPGVGGPMPKLADRLCADOECSHPISMAVALODYMAPDCR }\end{array}$

hMIAL 57 FINVKKGQQIYVYSKLVKENGAG-EFWA GSVYGDGQ-DEMEVVGYFPRNLVKEQRVYQEA

hMIA 61 FLTIHRGQVVYVFSKLK---GRGRLFWGGSVOGDYYGDIAARLGYFPSSIVREDQTLKPG

hMIAL 115 TKEVPTTDIDFFCE

C

mMial 1 MARILILLIGGLVVICAGHGVFMDKLSSKKLCADEECVYTISLARAQEDYNAPDCR

hMIAL 1 MARILLLFLPGLVAVCAVHGIFMDRLASKKLCADDECVYTISLASAQEDYNAPDCRFINV

mMial 61 KKGQQIYVYSKLVTENGAGEFWAGSVYGDHQDEMGIVGYFPSNLVKEQRVYQEATKEIPT

hMIAL 61 KKGQQIYVYSKLVKENGAGEFWAGSVYGDGQDEMGVVGYFPRNLVKEQRVYQEATKEVPT

mMial 121 TDIDFFCE

hMIAL 121 TDIDFFCE

FIG. 1. Sequence of MIAL. (A) CDNA nucleotide and deduced amino acid sequence of human MIAL. The putative signal peptide is underlined. In-frame stop codons are marked by asterisks. Consensus polyadenylation signals in the $3^{\prime}$-UTR are indicated by boldface type. (B) Amino acid alignment of human MIAL and MIA. (C) Amino acid alignment of mouse and human MIAL. In (B) and (C), black and gray boxes indicate identity and similarity, respectively, between the amino acid sequences. Conserved cysteines are marked by asterisks and a potential site for tyrosine O-sulfation is marked by an inverted triangle $(\nabla)$.

Doolittle plots (Kyte and Doolittle, 1982) showed an overall similar structure of hydrophobic and hydrophilic domains. Tyrosine 50 of both human and mouse MIAL may be O-sulfated, since it is preceded by two acidic residues (Bundgaard et al., 1997). No glycosylation sites are predicted in MIAL.

\section{Genomic Organization of the Human MIAL Gene}

The exon-intron structure of MIAL was deduced by alignment of MIAL CDNA with the sequence of the genomic clone 705D16. The predicted gene structure was confirmed by amplification and sequencing of exon-intron boundaries. The MIAL coding region is divided into four small exons of 115, 140, 108, and 24 bp that are distributed over a 2687-nucleotide chromo- somal region (Fig. 2). All splice junctions are in agreement with the GT-AG consensus sequence. A comparison of the genomic structure of MIAL with that of MIA revealed a highly conserved intron- exon structure in the codon phase (Fig. 2). Inspection of the sequence of genomic clone 705D16 showed that the intergenic distance between the MIAL initiation codon and the neighboring gene, small nuclear ribonucleoprotein polypeptide B2 (SNRPB2), is $7.4 \mathrm{~kb}$ and that MIAL and SNRPB2 are arranged in a head-to-tail configuration.

A $3-k b$ region $5^{\prime}$ to the initiation codon of human MIAL was analyzed for consensus binding sites for transcription factors using the TRANSFAC database. The search indicated binding sites (score >98) for SOX5 (SRY-related HMG box), SRY (sex-determining 


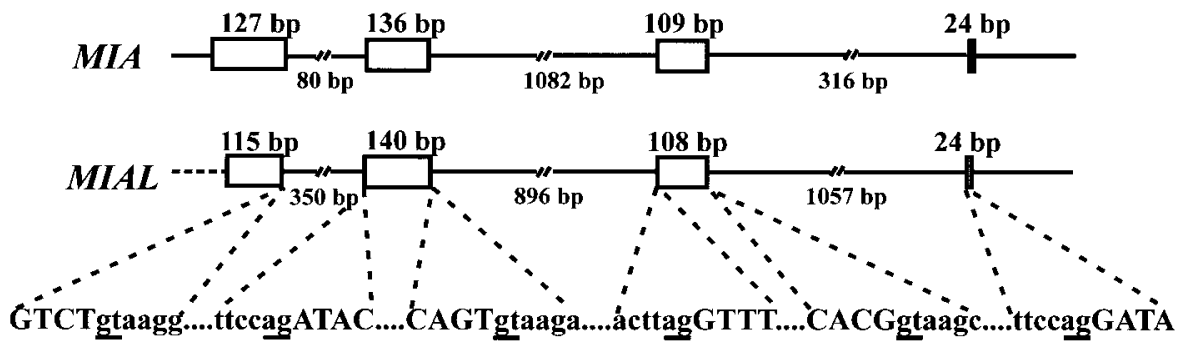

FIG. 2. Conserved exon structure of human MIAL and MIA genes. Coding sequence is indicated by boxes, and the lengths of exons and introns are given in basepairs. The sequences of exon-intron junctions of the MIAL gene are shown at the bottom, with coding sequence in capital letters and gt-ag consensus splice junction sequences underlined. The stippled line in MIAL indicates that the start of the $5^{\prime}$-UTR has not been defined.

factor), CRE-BP1 (CAMP-responsive element binding protein 1), MZF 1 (myeloid-specific zinc finger protein 1 ), runt-factor $A M L-1, C d x A$, and the homeodomain transcription factors $\mathrm{Hmx}$ and $\mathrm{Hm} \times 3$ (Table 1). The binding site for $\mathrm{Hmx}$ is also recognized by the homeodomain factor Nkx-2.5 (Amendt et al., 1999). Additional analysis identified three core binding sites (AACAAT) for SOX proteins (Mertin et al., 1999).

\section{Radiation Hybrid Mapping of the Mouse Mial Gene}

To establish the chromosomal localization of mouse Mial, PCR analysis was performed on DNA from the T31 mouse radiation hybrid panel (McCarthy et al., 1997). The data placed Mial on mouse chromosome 2 between markers D2Mit138 (LOD >3) 30.9 cR proximal and D2Mit259 (LOD >3) 20.8 cR distal in the T31 database, corresponding to a location between 79.4 and $80 \mathrm{cM}$ from the top of chromosome 2 . This chromosomal region shows conserved synteny to the human chromosomal region 20p11.22-p12.2, where the human genomic clone 705D16, containing MIAL, has been located by the Sanger Centre. No loci for nonsyndromic inner-ear defects have thus far been linked to human chromosome 20p11.22-p12.2 or to the syntenic murine region.

\section{TABLE 1}

\section{Predicted Transcription Factor Binding Sites in the 3-kb Region 5' to the Initiation Codon of Human MI AL}

\begin{tabular}{lcc}
$\begin{array}{c}\text { Transcription } \\
\text { factor }\end{array}$ & $\begin{array}{c}\text { Predicted binding site } \\
\text { in the MIAL promoter }\end{array}$ & $\begin{array}{c}\text { Position } 5^{\prime} \text { to } \mathrm{MIAL} \\
\text { initiation codon (bp) }\end{array}$ \\
\hline SOX 5 & TTAACAATAG & -239 to -248 \\
SRY & AAACAAA & -2224 to -2218 \\
& & -1480 to -1486 \\
& & -1217 to -1223 \\
CRE-BP1 & TTACGTAA & -435 to -429 \\
MZF 1 & AGTGGGGA & -456 to -463 \\
Runt factor AML-1 & TGTGGT & -2367 to -585 \\
Cdx A & ATTAATA & -1949 to -1955 \\
& AATAATA & -1949 to -1955 \\
Hmx1 and Hmx3 & TCAAGTG & -2694 to -2688 \\
& & -1738 to -1732 \\
& & -2139 to -2145 \\
\hline
\end{tabular}

Tissue Distribution of Human and Mouse MIAL mRNA

The temporal and spatial expression of MIAL in the developing human inner ear was investigated by in situ hybridization. No expression of MIAL was detected in the otic vesicle (the primordial inner ear) or in the inner ear at early stages of its formation (weeks 5, 6, and 7) (data not shown). At developmental week 9.5, when the labyrinths of the inner ear have largely assumed their final form, strong expression of MIAL was observed in the utricle, saccule, and ampullae of the semicircular canals (Fig. 3B). These structures belong to the vestibule, which is the organ that senses gravity and acceleration. Expression of MIAL was restricted to cells right beneath the epithelium that lines the fluidfilled labyrinths. I nterestingly, expression was highest, and the layer of MIAL-expressing cells was thickest, under regions of relatively well-developed sensory epithelia (e.g., the cristae ampullaris and utricular macula shown in Figs. $3 \mathrm{~A}$ and $3 \mathrm{G}$ ), in which the mechanosensitive hair cells of the inner ear are located. In the cochlea, where development of the sensory epithelium lags behind that of the vestibule, MIAL was also expressed by cells beneath the epithelium, but expression was weaker than in the vestibule (Fig. 3D). In regions within the semicircular canals with no developed sensory epithelium, MIAL expression was low (Fig. 3F). No expression of MIAL was observed in other embryonic or fetal tissues analyzed, which included brain, spinal cord, eye, developing kidney, heart, gut, liver, pharyngeal arches, limb buds, and vertebral anlage (data not shown).

We next used semiquantitative RT-PCR to analyze the expression of MIAL in human and murine inner ear and to compare it with that of MIA. The human and mouse specimens were analyzed at fetal weeks 8-10 and embryonic day 17, respectively. At these stages, the mouse inner ear is somewhat more developed than the human ear. Cells from various structures of the inner ear were dissected from tissue sections using the laser capture microdissection technique (Fig. 4C). For comparison, cells were also dissected from midbrain and retina. Thereafter, RNA was extracted and subjected to RT-PCR. In the mouse, a strong Mial signal was observed in cells from cochlea and vestibule, 

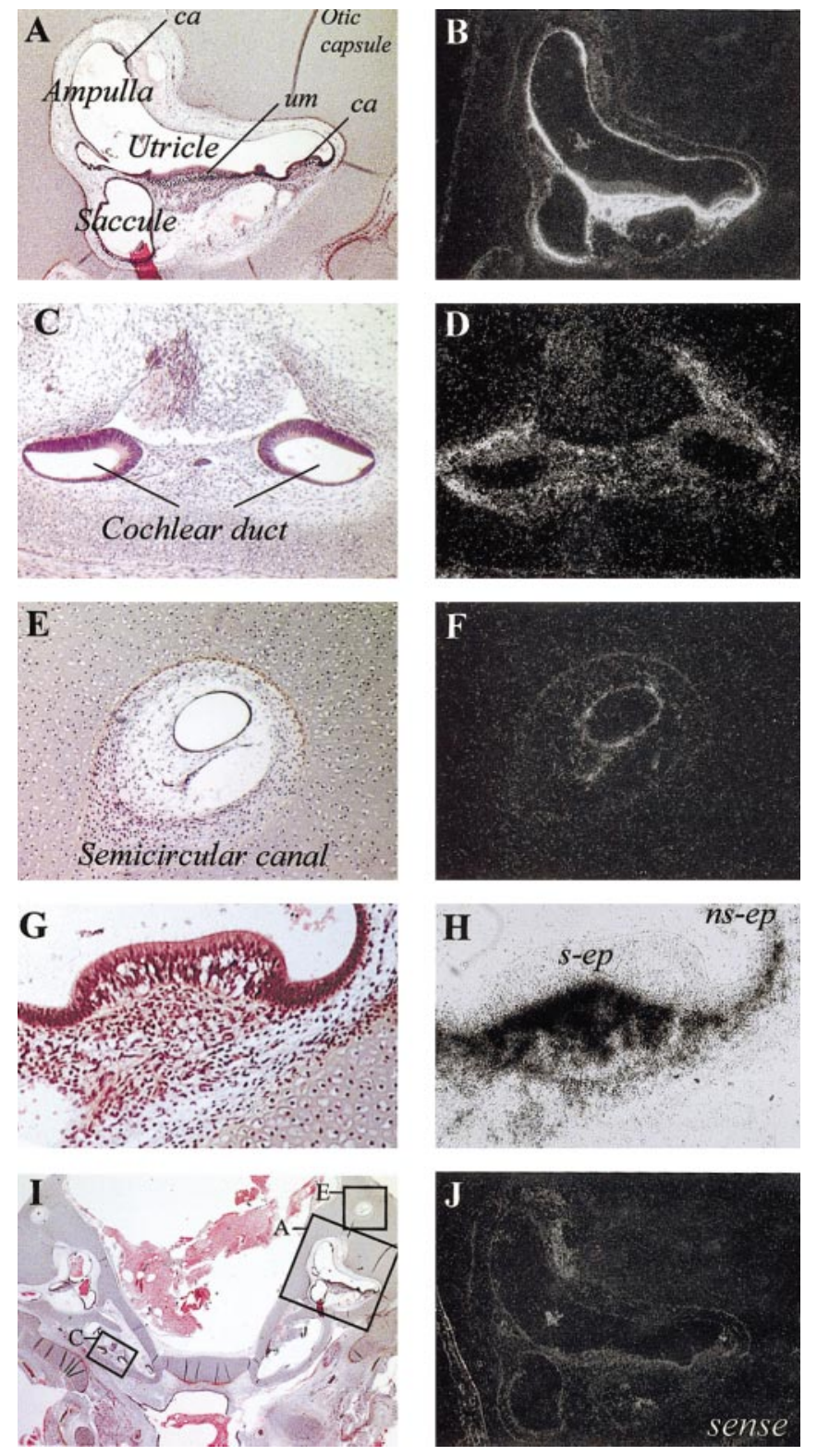

FIG. 3. In situ hybridization analysis of MIAL expression in the inner ear. A 9.5-week human fetal head was sectioned, mounted on a glass slide, and stained with hematoxylin and eosin (A, C, E, G, I). The adjacent section was hybridized with ${ }^{35} \mathrm{~S}$-labeled antisense MIAL riboprobe (B, D, F, H). Dark-field illumination shows MIAL expression in the utricle, saccule, and ampullae (B), in cochlea (D), and in the posterior semicircular canal (F). (H) Bright-field illumination of an ampulla at higher magnification reveals high-level MIAL expression in a cell layer beneath the sensory epithelium (s-ep) of crista ampullaris and a lower level of expression beneath the nonsensory epithelium (ns-ep). (I) Low-magnification view of the section with boxes indicating the regions magnified in $\mathbf{A - F}$. No hybridization signal was detected in sections hybridized with MIAL sense riboprobe as illustrated in (J), which is the adjacent section of (B). ca, crista ampullaris; um, utricular macula. Magnification: (A, B, J ) $\times 32$; (C-F) $\times 80$; (G, H) $\times 168$; (I) $\times 8$.

whereas no expression was detected in the otic capsule, midbrain, and retina (Fig. 4A). A similar distribution was observed for Mia (Fig. 4A). In human, MIAL was also expressed in the labyrinth of the inner ear (Fig. $4 \mathrm{~B})$. Whether the labyrinth was cochlear or vestibular could not be unambiguously determined due to morphological distortion of the fetal heads used for these experiments. No MIAL expression was detected in otic capsule, midbrain or retina. MIA showed weak expres-

$\mathbf{A}$
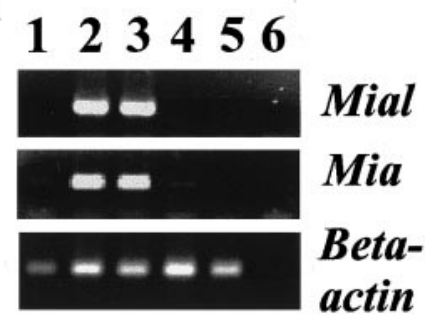

B

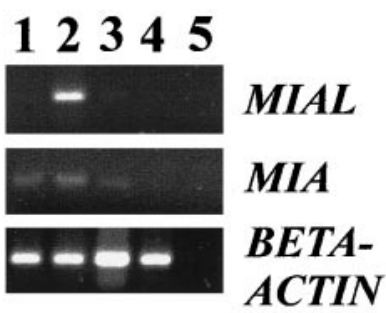

C
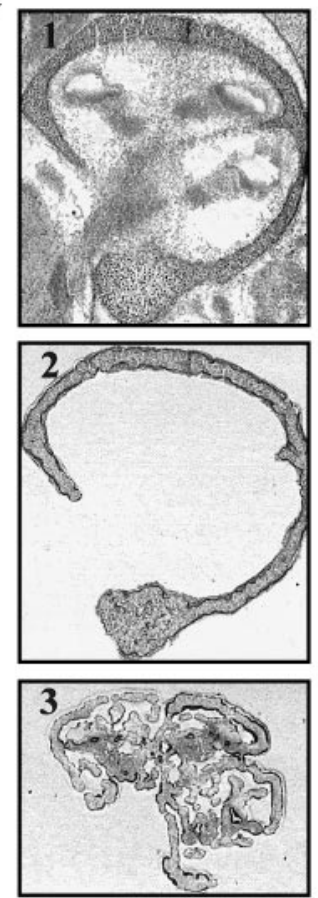

FIG. 4. RT-PCR analysis of MIAL and MIA mRNA expression in the inner ear. Sections of fetal mouse $(\mathbf{A})$ and fetal human $(\mathbf{B})$ head were mounted on glass slides and stained with hematoxylin and eosin. Cells from (A) otic capsule (1), cochlea (2), vestibule (3), midbrain (4), and retina (5) or (B) otic capsule (1), inner-ear labyrinth (2), midbrain (3), and retina (4) were microdissected by laser capture. A6 and B5 are negative controls $\left(\mathrm{H}_{2} \mathrm{O}\right)$. Total RNA was extracted, reverse-transcribed, and subjected to CDNA amplification using primers for MIAL, MIA or $\beta$-ACTIN. PCR products were resolved by el ectrophoresis on $2 \%$ agarose gels containing ethidium bromide. F or MIAL and MIA, 30-32 PCR cycles were used; for $\beta$-ACTIN, 27 cycles were used. The experiments were repeated three times with similar results. (C) Example of tissue microdissected by laser capture. The mouse cochlea prior to capture (1), captured cells from the otic capsule (2), and captured cells from cochlear labyrinth (3). 


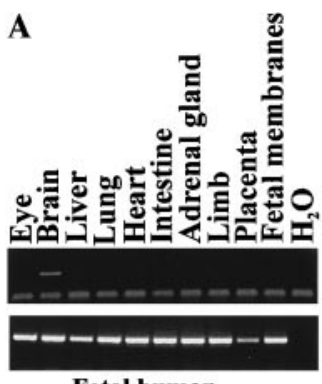

Fetal human

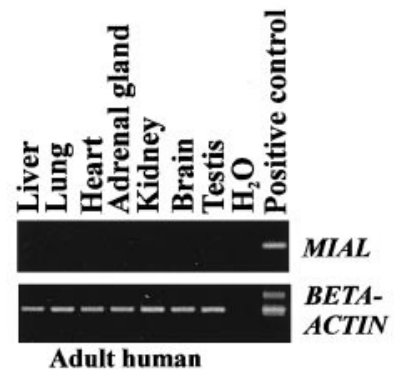

Adult human

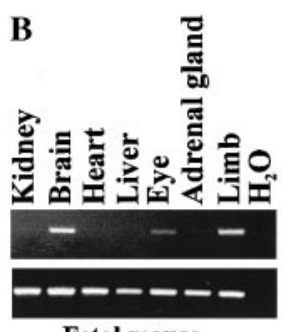

Fetal mouse

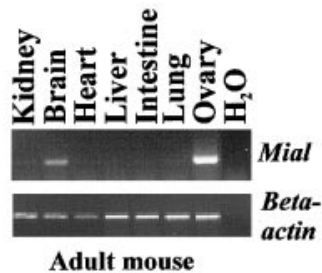

Adult mouse
C

Age (days): $7 \quad 10 \quad 24$

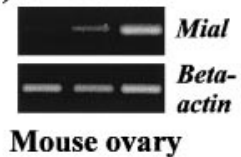

FIG.5. Tissue distribution of MIAL mRNA in mouse and human. Total RNA from fetal and adult tissues was reverse-transcribed and subjected to CDNA amplification using primers for MIAL or $\beta$-ACTIN. PCR products were resolved by electrophoresis on $2 \%$ agarose gels containing ethidium bromide. (A) Human fetal and adult tissues. Positive control is genomic DNA. (B) Mouse fetal and adult tissues. (C) Ovary from 7-, 10-, and 24-day-old mice. For MIAL, 30-32 PCR cycles were used; for $\beta$-ACTIN, 22 cycles were used. The experiments were repeated three times with similar results.

sion in the labyrinth and capsule of the human inner ear. A roughly similar signal for $\beta$-ACTIN in all tissues confirmed that the samples in Figs. $4 \mathrm{~A}$ and $4 \mathrm{~B}$ contained similar amounts of CDNA.

RT-PCR analysis of fetal and adult human tissues other than the inner ear detected expression of MIAL in whole fetal brain only (Fig. 5A). Thus, both in situ hybridization and RT-PCR suggest a remarkably restricted distribution of MIAL MRNA in humans and suggest that the inner ear may be the major site of synthesis. In the mouse, Mial mRNA also showed a narrow, but less restricted, tissue distribution, with signal detected in fetal whole brain, eye, and limb and in adult brain and ovary (Fig. 5B). In the ovary, expression of Mial appeared weakly at postnatal day 7 and reached adult levels at day 24 after birth (Fig. 5C). Finally, no Mial expression was detected in adult mouse testis, thyroid gland, skeletal muscle, or spleen (data not shown). The mRNA of $\beta$-ACTIN was present at roughly similar levels in all tissues.

Since expression of MIA is invariably observed in human malignant melanoma (Bosserhoff et al., 1999a), 30 metastatic melanoma cell lines were analyzed for MIAL expression by RT-PCR. However, MIAL was ex- pressed by 1 melanoma cell line only, in contrast to MIA, which was expressed by all of the cell lines (data not shown).

\section{Expression and Secretion of MIAL Protein by Cultured Cells}

We next performed an initial characterization of the protein product of the MIAL gene. Wefirst investigated whether the MIAL CDNA was able to direct the expression of a protein in transfected mammalian cells and whether the protein was secreted, as suggested by the presence of a signal peptide. The coding region plus 68 nucleotides of the $5^{\prime}-U T R$ of human MIAL CDNA was cloned into the mammalian expression vector pEFmyc, resulting in the fusion of the 9-amino-acid myc epitope tag to the C-terminus of MIAL. COS7 cells were transiently transfected with the plasmid, cultured for $48 \mathrm{~h}$, and then washed. Ten or $18 \mathrm{~h}$ after washing, cells and medium were collected and analyzed for the presence of MIAL by immunoblotting for the myc epitope tag. As shown in Fig. 6A (left panel),

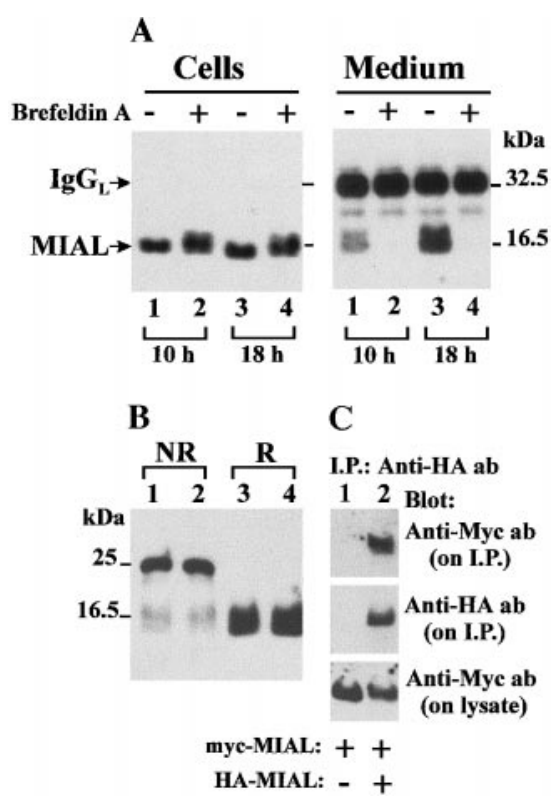

FIG. 6. Expression, secretion, and homodimer formation of MIAL protein in mammalian cells. COS7 cells were transfected with mammalian expression vector containing C-terminally epitopetagged MIAL and cultured for $48 \mathrm{~h}$. (A) To assay for secretion of MIAL, cells expressing myc-MIAL were washed and incubated in serum-free medium in the presence or absence of $1 \mu \mathrm{g} / \mathrm{ml}$ brefel din A. After 10 or $18 \mathrm{~h}$, cells and medium were collected and analyzed for the presence of MIAL protein by SDS-PAGE and immunoblotting with antibody to the myc epitope tag. (B) Cells expressing myc-MIAL were lysed in nonreducing (NR) or reducing, i.e., containing $\beta$-mercaptoethanol, (R) SDS-PAGE sample buffer. Lysates of duplicate determinations were subjected to SDS-PAGE and immunoblotting with antibody to the myc epitope tag. (C) Cells were transfected with myc-MIAL together with empty vector $(-)$ or $\mathrm{HA}-\mathrm{MIAL}$. After $48 \mathrm{~h}$, cells were lysed and subjected to immunoprecipitation (I.P.) with antibody to the HA tag. Aliquots of the precipitates were subjected to immunoblotting with antibody to the myc tag (top) or to the HA tag (middle). Preimmunoprecipitation lysates were subjected to immunoblotting with antibody to the myc tag (bottom). The experiments were performed two $(\mathbf{A})$ or three $(\mathbf{B}$ and $\mathbf{C})$ times with similar results. 
the transfected cells expressed one protein product of $\sim 15 \mathrm{kDa}$, which is in agreement with the size predicted by the CDNA sequence. Moreover, MIAL protein was also present in the medium, where it accumulated over time (Fig. 6A, compare lanes 1 and 3 in the right-hand panel), indicating that MIAL is synthesized into the endoplasmic reticulum and secreted by the cells. To support this conclusion, parallel cell cultures were treated with the fungal metabolite brefeldin A, which inhibits the translocation of vesicles from the endoplasmic reticulum to the Golgi apparatus and thereby blocks protein secretion via the Golgi apparatus (Misumi et al., 1986). Treatment with brefeldin A completely abolished accumulation of MIAL protein in the medium (Fig. 6A, lanes 2 and 4, right panel). MIAL from brefeldin A-treated cells migrated as a highermolecular-weight species compared to that of untreated cells (Fig. 6A, left panel), suggesting that MIAL is subject to posttranslational processing in the Golgi apparatus.

MIAL and MIA contain four conserved cysteine residues that may be involved in disulfide bridge formation. To investigate this possibility, COS7 cells expressing myc-MIAL were lysed in reducing or nonreducing sample buffer and analyzed by SDSPAGE and immunoblotting. I nterestingly, nonreduced MIAL migrated as a species approximately twice the size of reduced MIAL (Fig. 6B), suggesting that MIAL is assembled into a covalently linked homodimer in the cells. To address this possibility further, we first cloned MIAL into another expression vector, resulting in Cterminal tagging of MIAL with the 9-amino-acid $\mathrm{HA}$ tag. HA-MIAL was found to behave in the same way as myc-MIAL with respect to subcellular localization, secretion, and double molecular size in nonreducing SDS-PAGE (data not shown). Myc-MIAL and HAMIAL were then coexpressed in COS7 cells, followed by Iysis of the cells and immunoprecipitation with antibody to the HA tag. I mmunoblotting of the precipitates with anti-myc antibody showed that HA-MIAL was able to coprecipitate myc-MI AL (Fig. 6C, lane 2, upper panel). The anti-HA antibody did not precipitate mycMIAL from cells that were not cotransfected with HAMIAL (Fig. 6C, lane 1, top panel). I mmunoblotting of the preprecipitation lysates showed that myc-MIAL was expressed at the same level under both transfection conditions (Fig. 6C, bottom panel). This experiment demonstrates directly that MIAL forms a homodimer in cells.

Human and mouse MIAL proteins contain a potential site for tyrosine O-sulfation (Glu-Asp-Tyr ${ }^{50}$ ). To investigate whether MIAL is sulfated, cells expressing myc-MIAL were metabolically labeled with $\left[{ }^{35} \mathrm{~S}\right] \mathrm{sul}$ fate. Thereafter, secreted MIAL was isolated from the culture medium by immunoprecipitation and analyzed by SDS-PAGE under reducing conditions and autoradiography. As shown in Fig. 7B, lane2, the precipitates contained a sulfated protein of approximately $15 \mathrm{kDa}$, corresponding to the size of a MIAL monomer. Sulfa-

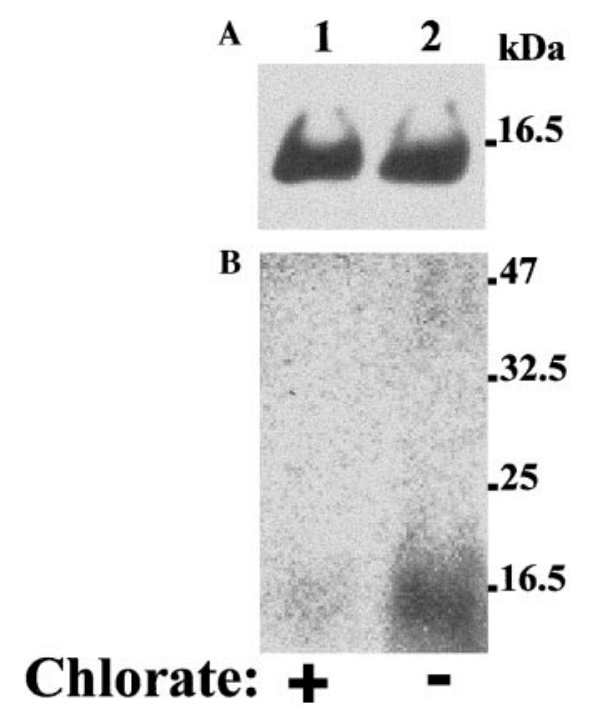

FIG. 7. Sulfation of MIAL protein in COS7 cells. Cells were transiently transfected with myc epitope-tagged MIAL and cultured for $48 \mathrm{~h}$. Cells were then washed and incubated with $\left[{ }^{35} \mathrm{~S}\right]$ sulfate in serum-free medium in the presence or absence of $25 \mathrm{mM}$ sodium chlorate. After $18 \mathrm{~h}, \mathrm{MIAL}$ was immunoprecipitated from the culture medium with antibody to the myc tag. Aliquots of the precipitates were subjected to SDS-PAGE (reducing conditions) and analyzed by immunoblotting for the myc epitope tag (A) or by autoradiography (B).

tion of MIAL was nearly abolished by treatment of cells with chlorate during ${ }^{35} \mathrm{~S}$ labeling (Fig. 7B, lane 1). Chlorate competitively inhibits the formation of $3^{\prime}$ phosphoadenosine $5^{\prime}$-phosphosulfate, which is the sulfate donor in cellular sulfation reactions (Farley et al., 1978). Immunoblotting for the myc tag showed that equal amounts of MIAL were present in the precipitates from untreated and chlorate-treated cells (Fig. 7A). MIAL immunoprecipitated from cell lysates was also sulfated (data not shown).

The subcellular localization of MIAL in transfected COS7 cells was analyzed by immunocytochemistry. Immunostaining for the myc epitope tag revealed intense staining in a perinuclear structure resembling that of the Golgi apparatus and less intense staining in a cytosolic network that presumably corresponds to the endoplasmic reticulum (Fig. 8A, panel 1). In contrast, no staining was detected in the nucleus. By doubleimmunostaining, the perinuclear $\mathrm{MIAL}$ signal was found to overlap with the signal of the Golgi marker protein, 58K, supporting the conclusion that MIAL was present in the Golgi apparatus (Fig. 8A, compare panels 1 and 2). Moreover, treatment of cells with brefeldin A redistributed MIAL as well as 58K from a predominantly perinuclear to a predominantly cytoplasmic localization (Fig. 8A, panels 3 and 4). Truncation of the putative signal peptide resulted in a mutant, $M I A L_{23}$ 128, with completely different subcellular localization compared to wildtype MIAL. MIAL $\mathrm{AL}_{23-128}$ was uniformly distributed in the cytoplasm and the nucleus and showed no Golgi localization (Fig. 8A, panels 5 and 6). Accordingly, brefeldin A did not affect the subcellular distribution of $M I A_{23-128}$ in contrast to wildtype MIAL 
(Fig. 8A, panels 7 and 8). I mmunobl otting showed that $M I A L_{23-128}$ was expressed at the expected size, but at a lower level than wildtype MIAL (Fig. 8B).

Identification of an Allelic Variant of Human MIAL That Does Not Express Protein

During the cloning of the human MIAL gene, we discovered a polymorphism in the initiation codon. The allelic variant (termed a) contained ACG (threonine) as codon 1 as opposed to ATG of the wildtype MIAL allele (termed A) (Fig. 9A). The T-to-C transition in the MIAL variant creates a cleavage site for the endonuclease Bbsl, allowing genotype identification by Bbsl digestion of PCR-amplified genomic sequence that includes the initiation codon of MIAL (Fig. 9B). In 505 unrelated individuals subjected to genotype analysis, 456 (90.3\%) were found to be AA homozygous, 48 (9.5\%) were Aa heterozygous, and $1(0.2 \%)$ was aa homozygous. The variant allele of MI AL also contained a c-to-g transversion at position -29 in the $5^{\prime}$-UTR (Fig. 9A).

We next investigated whether the MIAL allele containing ACG in the initiation codon could direct the synthesis of MIAL protein. The variant allele was used to generate an expression plasmid, myc-MIAL(Met1Thr), that was identical to the construct containing wildtype MIAL except for ACG as codon 1. As shown in Fig. 9C, no MIAL protein was expressed by COS7 cells transfected with myc-MIAL (Met1Thr), whereas transfection with wildtype myc-MIAL plasmid resulted in robust expression.

\section{DISCUSSION}

In this study we have discovered and cloned a human gene and the corresponding mouse CDNA and performed an initial characterization of the gene, mRNA, and protein. The gene was named MIAL since similarity in exon structure and primary sequence revealed an evolutionary relationship with MIA. Very recently, Robertson et al. (2000) reported CDNA cloning of human and mouse OTOR, which are identical to human and mouse MIAL, respectively. In addition, the CDNA of the chicken and bullfrog orthologues were also isolated. All MIA and MIAL sequences reported show conservation of size, a putative signal peptide, and four cysteines. Thus the two genes constitute a small and unique family encoding proteins that are likely to have a similar three-dimensional structure.

Like MIA, MIAL was found to encode an extracellular protein. In transfected cells, MIAL was secreted into the medium via the Golgi apparatus, as evidenced by immunocytochemistry and accumulation of MIAL in the culture medium, which could be blocked by the Golgi inhibitor brefeldin A. Apparently, secretion of MIAL is directed by the predicted signal peptide, since the deletion mutant MIAL $_{23-128}$ was absent from the Golgi apparatus and showed abnormal cytoplasmic and nuclear localization compared to wildtype MIAL.
We have obtained evidence for two types of posttranslational modification of MIAL. First, MIAL forms a covalently linked homodimer, as evidenced by size in nonreducing electrophoresis and by coimmunoprecipitation experiments with differentially epitope-tagged MIAL proteins (Fig. 6). Second, MIAL is sulfated as shown by metabolic labeling with $\left.{ }^{35} \mathrm{~S}\right]$ sulfate (Fig. 7). Sulfation may occur at $\mathrm{Tyr}^{50}$, which is situated in a motif for tyrosine O-sulfation and because MIAL is not predicted to be glycosylated, and hence should not be sulfated on sugar residues. The two modifications may be important for MIAL function. Thus, tyrosine sulfation is known to regulate protein-protein interaction of extracellular molecules (Kehoe and Bertozzi, 2000), and homodimerization is essential for the biological activity of many extracellular proteins. It is likely that MIA may also be sulfated and form a dimer, since both the tyrosine O-sulfation motif and the cysteines are conserved.

MIAL showed remarkably restricted expression in human tissues when analyzed by in situ hybridization and RT-PCR. Expression was detected solely in fetal inner ear and brain. Moreover, we cannot exclude the possibility that the signal detected by RT-PCR in fetal brain may derive from inner-ear tissue. In agreement with this possibility, MIAL ESTs (11 all together) have been reported only from fetal cochlea and not from brain or any other human tissue. It is ther efore possible that in humans, MIAL is expressed specifically in the inner ear. In the mouse, Mial showed less restricted tissue distribution, since it was detected by RT-PCR also in eye, limb, ovary, and brain. Our data are in accordance with Northern blot analysis by Robertson et al. (2000), who, in multiple human and chicken tissues analyzed, detected strong OTOR expression only in cochlea and a very weak signal in chicken eye.

Within the inner ear, MIAL was expressed by cells located beneath the epithelium that lines the labyrinth. Expression seemed particularly high under the sensory epithelium, in particular beneath the quite advanced sensory epithelial structures of utricle and cristae ampullares of fetal human week 9.5 inner ear. At this fetal age, the sensory structures of the cochlea are poorly developed, which may be the reason that MIAL showed less robust expression in the cochlea than in the vestibule. Consistent with our findings, in situ hybridization analysis by Robertson et al. (2000) showed strong OTOR expression in cell layers beneath the well-developed sensory epithelium of late embryonic and posthatching chicken cochlea. The spatial conservation of MIAL expression in human and chicken, which are evolutionarily distant, suggests an important role for MIAL in the inner ear. The distribution of MIAL in the inner ear also raises the possibility that expression of MIAL is induced by signals derived from the sensory epithelium.

RT-PCR suggested that MIA and MIAL are co-expressed in the murine, and perhaps also the human, 
A

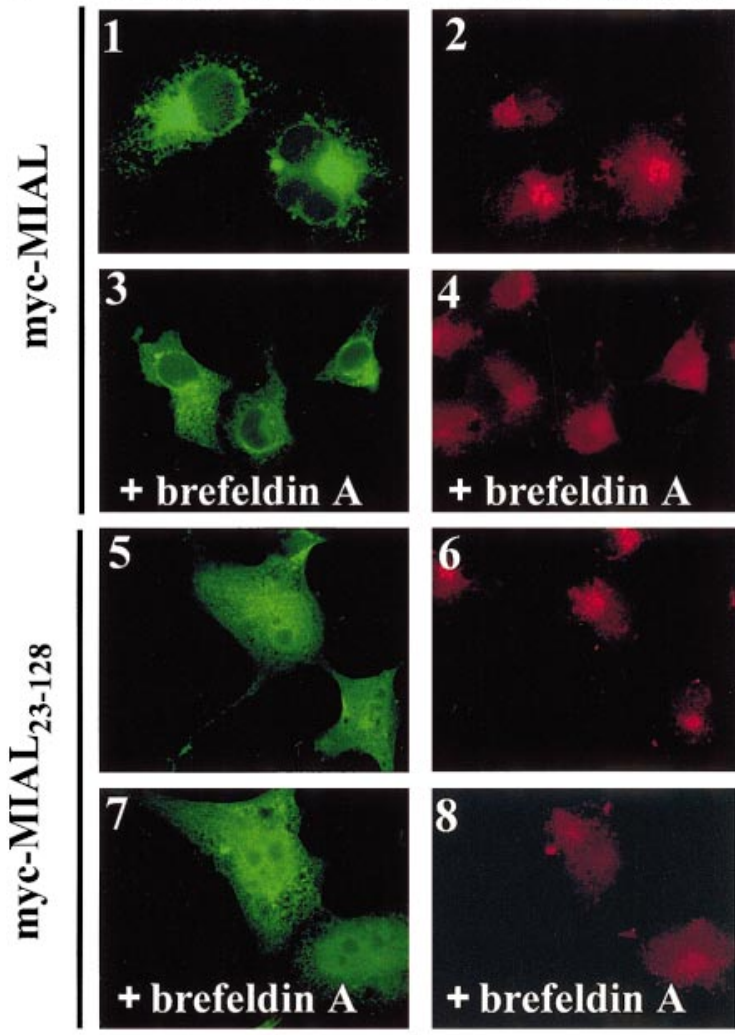

B

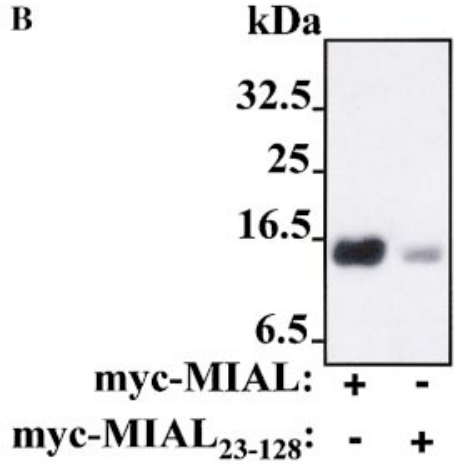

FIG. 8. Subcellular localization of $M I A L$ and $M I A L_{23-128}$ in COS7 cells. (A) Cells were transiently transfected with myc epitope-tagged MIAL or MIAL $23-128$, cultured for $24 \mathrm{~h}$, and incubated with or without $1 \mu \mathrm{g} / \mathrm{ml}$ brefeldin A for $2 \mathrm{~h}$. Thereafter, cells were fixed and subjected to double-immunofluorescence staining for the myc epitope tag (green) and for the Golgi marker 58K (red). (B) COS7 cells expressing myc-MIAL or myc-MIAL $23-128$ were lysed under reducing conditions and subjected to SDS-PAGE and immunoblotting with antibody to the myc epitope tag. The experiments were performed three times with similar results.

inner ear. However, there may be an important quantitative difference in the expression level. Thus, Dietz and Sandell (1996) failed to detect MIA expression in the E13.5 mouse inner ear by in situ hybridization. Presumably, the sensitive RT-PCR technique used here was able to detect low levels of MIA expression in the inner ear. Clearly discordant expression of MIA and MIAL was observed in human melanoma cells. MIAL was expressed by only 1 of 30 melanomas analyzed, whereas MIA was expressed throughout. A com- parison of regulatory elements in the promoter region of MIA and MIAL provides several clues to distinct transcriptional regulation of the two genes. The MIA promoter contains binding sites for the transcription factors Sox9, AP-2, and NF- $\mathrm{B}$, which have proven
A

A

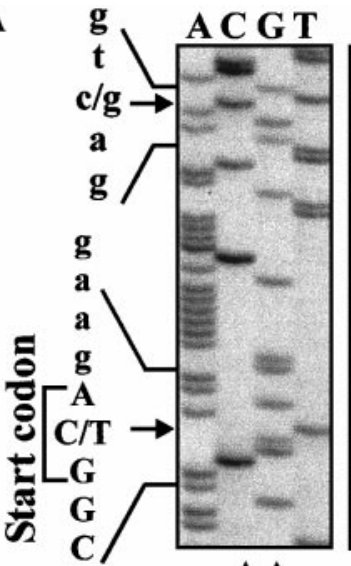

Aa

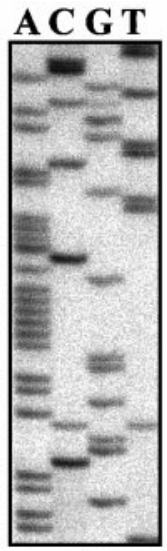

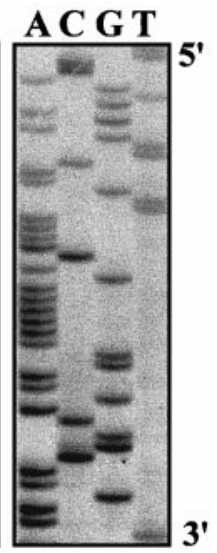

aa
B

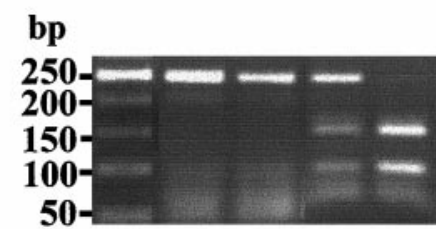

Genotype: AA AA Aa aa

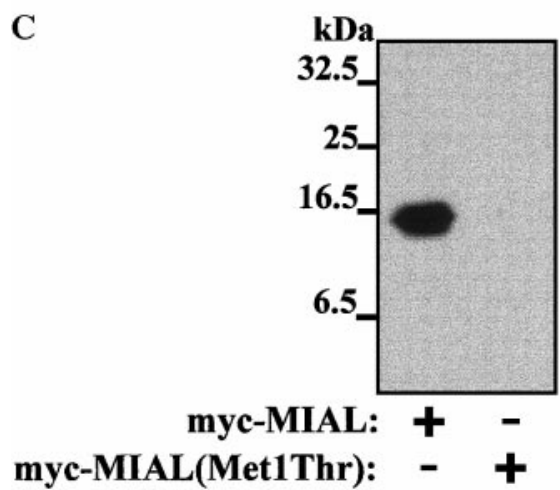

FIG. 9. A polymorphism in the initiation codon of human MIAL that abolishes protein expression. (A) Nucleotide sequence of genomic DNA around the initiation codon of human MIAL from a wildtype homozygote (AA), a heterozygote (Aa), and a homozygote (aa) for ACG in the initiation codon. The allelic variant, but not wildtype $M I A L$, contains a Bbsl restriction site $\left(5^{\prime} \operatorname{GAAGAC}\left(\mathrm{N}_{2}\right)\right)$. Coding sequence is shown in capital letters. (B) Restriction digestion analysis of initiation codon polymorphism in the MIAL gene. Genomic DNA from four individuals was PCR-amplified to produce a 254-bp fragment containing the initiation codon of MIAL. The PCR products were digested with Bbsl, which cleaves the ACG allele into fragments of 151 and 103 bp. One 254-bp fragment identifies an AA homozygote, three fragments of 254, 151, and 103 bp identify an Aa heterozygote, whereas two fragments of 151 and 103 bp identify an aa homozygote. The first lane contains a 50-bp ladder molecularweight marker. (C) COS7 cells were transfected with plasmid containing myc-tagged wildtype MIAL or the allelic variant, mycMIAL(Met1Thr). Forty-eight hours after transfection, cells were lysed and subjected to SDS-PAGE under reducing conditions and immunoblotting with antibody to the myc epitope tag. 
functional in promoting MIA transcription in chondrocytes or melanoma cells in vitro (Bosserhoff et al., 1996; Xie et al., 1998, 1999). In contrast, the MIAL promoter contains no AP-2 or NF- $\kappa$ B sites. The MIAL promoter contains three core SOX binding elements, but none with optimal flanking sequence for SOX9 binding (Mertin et al., 1999).

In humans, we discovered a variant MIAL allele with ACG as codon 1 . In transfection experiments, this allele was unable to direct MIAL protein expression. ACG in codon 1 is well known to result in little or no protein translation (discussed in Kozak, 1996). Genetic diseases where the start ATG has mutated to ACG include $\alpha$-thalassemia (Pirastu et al., 1984), $\beta$-thalassemia (Beris et al., 1993), Tay-Sachs disease (Harmon et al., 1993), and variegate porphyria (Frank et al., 1999). In the rare cases where a non-ATG serves as a start site, introduction of ATG by mutagenesis causes large increases in protein yield (Kozak, 1996).

Considering the severe effect on protein expression, the ACG allele was found to be surprisingly frequent. In the Danish population, $9.5 \%$ are heterozygous for the ACG allele, and in 505 individuals, one ACG homozygote was identified. The homozygous male was 60 years old and had no unusual medical record or apparent phenotype. An audiogram obtained from the homozygous individual showed bilateral hearing loss at the higher frequencies. Hearing loss of the better hearing ear was $5 \mathrm{~dB}$ at $1000 \mathrm{~Hz}, 10 \mathrm{~dB}$ at $2000 \mathrm{~Hz}, 20 \mathrm{~dB}$ at $4000 \mathrm{~Hz}$, and $30 \mathrm{~dB}$ at $8000 \mathrm{~Hz}$. Vestibular function was not investigated. The hearing loss of the homozygote is within normal range when considering his age. However, the normal hearing loss by the elderly is believed to contain an important genetic component (Steel, 2000). Moreover, the penetrance of several deafness genes varies considerably from individual to individual, pending on genetic background or environment, as for instance prolonged noise stress (Steel, 2000).

Extracellular matrix and cell adhesion molecules are believed to play a prominent role in development of the complex structures of the mammalian inner ear (reviewed in Legan and Richardson, 1997). Several forms of nonsyndromic deafness or balance defect that result from mutations in genes encoding extracellular proteins have been described in humans and mice. These genes include TECTA (Verhoeven et al., 1998), COL11A2 (McGuirt et al., 1999), COCH (Robertson et al., 1998), and Otog (Simmler et al., 2000). The importance of extracellular matrix proteins in inner ear function, the inner ear-restricted MIAL expression pattern, and the existence of an inactive allele suggest that MIAL may contribute to nonsyndromic hearing impairment or balance defect in humans. Identification and examination of additional homozygotes for the MIAL ACG allele will provide a powerful means of establishing the role of MIAL in normal function and disease of the inner ear.

\section{ACKN O WLEDGMENTS}

Wethank Dr. H. Eiberg, the Panum I nstitute, for DNA samples, D. Nolting, the Panum Institute, for preparing tissue sections for laser capture microdissection, Professor A. Parving, Bispebjerg Hospital, for performing hearing tests, B. Kofoed, Glostrup Hospital, for help with coimmunoprecipitation experiments, J . Augé and Dr. F. EnchaRazavi, Hôpital Necker, for help with the in situ hybridization experiments, Dr. P. Guldberg, Danish Cancer Society, for melanoma CDNA, Dr. J . R. Bundgaard, Rigshospitalet, for advice on the sulfation experiment, and Dr. G. Hansen, the Panum Institute, for antiGolgi 58K antibody. This work was supported by grants from the Danish Biotechnological Research and Development Programme 1996-1998, the Danish Cancer Society, the Danish Research Center for Growth and Regeneration, the Danish Research Council, Novo Nordisk Foundation, Åge Bangs Foundation, the German Genome Program/Deutsche Forschungsanstalt für Luft- und Raumfahrt e. V. (Grant 4763), the EU-Commission (BMH4-CT97-2268), and the Danish Environmental Research Programme.

\section{REFERENCES}

Amendt, B. A., Sutherland, L. B., and Russo, A. F. (1999). Transcriptional antagonism between $\mathrm{Hmx1}$ and $\mathrm{Nkx2.5}$ for a shared DNAbinding site. J . Biol. Chem. 274: 11635-11642.

Beris, P., Darbellay, R., Speiser, D., Kirchner, V., and Miescher, P. A. (1993). De novo initiation codon mutation (ATG $\rightarrow$ ACG) of the beta-globin gene causing beta-thalassemia in a Swiss family. Am. J. Hematol. 42: 248-253.

Blesch, A., Bosserhoff, A. K., Apfel, R., Behl, C., Hessdoerfer, B., Schmitt, A., J achimczak, P., Lottspeich, F., Buettner, R., and Bogdahn, U. (1994). Cloning of a novel malignant melanomaderived growth-regulatory protein, MIA. Cancer Res. 54: 56955701.

Bosserhoff, A. K., Golob, M., Buettner, R., Landthaler, M., and Hein, R. (1998). MIA ("melanoma inhibitory activity"). Biological functions and clinical relevance in malignant melanoma. Hautarzt 49: 762-769.

Bosserhoff, A. K., Hein, R., Bogdahn, U., and Buettner, R. (1996). Structure and promoter analysis of the gene encoding the human melanoma-inhibiting protein MIA. J . Biol. Chem. 271: 490- 495.

Bosserhoff A. K., Hein, R., Wach, F., and Buettner, R. (1997a). Function of MIA in metastasis of malignant melanoma. Proc. Am. Assoc. Cancer Res. 38: 290.

Bosserhoff, A. K., Kaufmann, M., Kaluza, B., Bartke, I., Zirngibl, H., Hein, R., Stolz, W., and Buettner, R. (1997b). Melanoma-inhibiting activity, a novel serum marker for progression of malignant melanoma. Cancer Res. 57: 3149-3153.

Bosserhoff, A. K., Kondo, S., Moser, M., Dietz, U. H., Copeland, N. G., Gilbert, D. J ., J enkins, N. A., Buettner, R., and Sandell, L. J . (1997c). Mouse CD-RAP/MIA gene: Structure, chromosomal localization, and expression in cartilage and chondrosarcoma. Dev. Dyn. 208: 516-525.

Bosserhoff, A. K., Lederer, M., Kaufmann, M., Hein, R., Stolz, W., Apfel, R., Bogdahn, U., and Buettner, R. (1999a). MIA, a novel serum marker for progression of malignant melanoma. Anticancer Res. 19: 2691-2693.

Bosserhoff, A. K., Moser, M., Hein, R., Landthaler, M., and Buettner, R. (1999b). In situ expression patterns of melanoma-inhibiting activity (MIA) in melanomas and breast cancers. J . Pathol. 187: $446-454$.

Bundgaard, J . R., Vuust, J ., and Rehfeld, J . F . (1997). New consensus features for tyrosine O-sulfation determined by mutational analysis. J . Biol. Chem. 272: 21700-21705.

Chomczynski, P., and Sacchi, N. (1987). Single-step method of RNA isolation by acid guanidinium thiocyanate-phenol-chloroform extraction. Anal. Biochem. 162: 156-159. 
Deichmann, M., Benner, A., Bock, M., J ackel, A., Uhl, K., Waldmann, V., and Naher, H. (1999). S100-Beta, melanoma-inhibiting activity, and lactate dehydrogenase discriminate progressive from nonprogressive. American J oint Committee on Cancer Stage IV Melanoma. J . Clin. Oncol. 17: 1891-1896.

Dietz, U. H., and Sandell, L. J . (1996). Cloning of a retinoic acidsensitive mRNA expressed in cartilage and during chondrogenesis. J . Biol. Chem. 271: 3311-3316.

Farley, J. R., Nakayama, G., Cryns, D., and Segel, I. H. (1978). Adenosine triphosphate sulfurylase from Penicillium chrysogenum equilibrium binding, substrate hydrolysis, and isotope exchange studies. Arch. Biochem. Biophys. 272: 376-390.

Frank, J., McGrath, J . A., Poh-Fitzpatrick, M. B., Hawk, J . L., and Christiano, A. M. (1999). Mutations in the translation initiation codon of the protoporphyrinogen oxidase gene underlie variegate porphyria. Clin. Exp. Dermatol. 24: 296-301.

Grove, J. R., Price, D. J ., Banerjee, P., Balasubramanyam, A., Ahmad, M. F., and Avruch, J . (1993). Regulation of an epitope-tagged recombinant Rsk-1 S6 kinase by phorbol ester and erk/MAP kinase. Biochemistry 32: 7727-7738.

Guldberg, P., thor Straten, P., Birck, A., Ahrenkiel, V., Kirkin, A. F., and Zeuthen, J . (1997). Disruption of the MMAC1/PTEN gene by deletion or mutation is a frequent event in malignant melanoma. Cancer Res. 57: 3660-2663.

Harmon, D. L., Gardner-Medwin, D., and Stirling, J . L. (1993). Two new mutations in a late infantile Tay-Sachs patient are both in exon 1 of the beta-hexosaminidase alpha subunit gene. J . Med. Genet. 30: 123-128.

Keats, B. J. B., and Berlin, C. I. (1999). Genomics and hearing impairment. Genome Res. 9: 7-16.

Kehoe, J. W., and Bertozzi C. J . (2000). Tyrosine sulfation: A modulation of extracellular protein-protein interactions. Chem. Biol. 7: R57-R61.

Kondo, S., Cha, S. H., Oganesian, A., Xie, W., and Sandell, L. J . (1998). Regulation and function of CD-RAP, a new cartilage-specific protein. Orthop. Trans. 21: 848.

Kozak, M. (1996). I nterpreting cDNA sequences: Some insights from studies on translation. Mamm. Genome 7: 563-574.

Kyte, J ., and Doolittle, R. F. (1982). A simple method for displaying the hydropathic character of a protein. J . Mol. Biol. 157: 105-132.

Legan, P. K., and Richardson, G. P. (1997). Extracellular matrix and cell adhesion molecules in the developing inner ear. Semin. Cell. Dev. Biol. 8: 217-224.

McCarthy, L. C., Terrett, J ., Davis, M. E., Knights, C. J ., Smith, A. L., Critcher, R., Schmitt, K., Hudson, J., Spurr, N. K., and Goodfellow, P. N. (1997). A first-generation whole genome-radiation hybrid map spanning the mouse genome. Genome Res. 7: 1153-1161.

McGuirt, W. T., Prasad, S. D., Griffith, J ., Kunst, H. P. M, Green, G. E., Shpargel, K. B., Runge, C., Huybrechts, C., Mueller, R., Lynch, E., King, M.-C., Brunner, H. G., Cremers, C. W. R. J ., Takanosu, M., Li, S.-W., Arita, M., Mayne, R., Prockop, D. J ., Camp, G. V., and Smith, R. J . H. (1999). Mutations in COL 11A2 cause nonsyndromic hearing loss (DFNA13). Nat. Genet. 23: 413419.

Mertin, S., McDowall, S. G., and Harley, V. R. (1999). The DNAbinding specificity of SOX9. Nucleic Acids Res. 27: 1359-1364.

Misumi, Y., Miki, K., Takatsuki, A., Tamura, G., and Ikehara, Y. (1986). Novel blockade by brefeldin A of intracellular transport of secretory proteins in cultured rat hepatocytes. J . Biol. Chem. 261: 11398-11403.

Neame, P. J., Tapp, H., and Azizan, A. (1999). Noncollagenous, nonproteoglycan macromolecules of cartilage. Cell. Mol. Life Sci. 55: 1327-1340.

Petit, C. (1996). Genes responsible for human hereditary deafness: Symphony of a thousand. Nat. Genet. 14: 385-391.

Pirastu, M., Saglio, G., Chang, J . C., Cao, A., and Kan, Y. W. (1984). I nitiation codon mutation as a cause of alpha thalassemia. J . Biol. Chem. 259: 12315-12317.

Robertson, N. G., Khetarpal, U., Gutiérrez-Espeleta, G. A., Bieber, F. R., and Morton, C. C. (1994). I solation of novel and known genes from a human fetal cochlear cDNA library using subtractive hybridization and differential screening. Genomics 23: 43-50.

Robertson, N. G., Heller, S., Lin, J . S., Resendes, B. L., Weremowicz, S., Denis, C. S., Bell, A. M., Hudspeth, A. J ., Morton, C. C. (2000). A novel cochlear gene, OTOR: Identification, expression analysis, and chromosomal mapping. Genomics 66: 242-248.

Robertson, N. G., Lu, L., Heller, S., Merchant, S. N., Eavey, R. D., McKenna, M., Nadol, J . B., J r., Miyamoto, R. T., Linthicum, F. H. J r., Lubianca Neto, J . F., Hudspeth, A. J ., Seidman, C. E., Morton, C. C., and Seidman, J. G. (1998). Mutations in a novel cochlear gene cause DFNA9, a human nonsyndromic deafness with vestibular dysfunction. Nat. Genet. 20: 299-303.

Shyng, Y. C., Devlin, H., Riccardi, D., and Sloan, P. (1999). Expression of cartilage-derived retinoic acid-sensitive protein during healing of the rat tooth-extraction socket. Arch. Oral. Biol. 44: 751-757.

Simmler, M.-C., Cohen-Salmon, M., El-mraoui, A., Guillaud, L., Benichou, J .-C., Petit, C., and Panthier, J .-J . (2000). Targeted disruption of Otog results in deafness and severe imbalance. Nat. Genet. 24: 139-143.

Steel, K. P. (2000). New interventions in hearing impairment. Br. Med. J . 320: 622-625.

Van Camp, G., and Smith, R. (2000). Hereditary Hearing Loss home page. World Wide Web URL: http://hgins.uia.ac.be/dnalab/hhh/.

Verhoeven, K., Van Laer, L., Kirschhofer, K., Legan, P. K., Hughes, D. C., Schatteman, I., Verstreken, M., Van Hauwe, P., Coucke, P., Chen, A., Smith, R. J ., Somers, T., Offeciers, F. E., Van de Heyning, P., Richardson, G. P., Wachtler, F., Kimberling, W. J ., Willems, P. J ., Govaerts, P. J ., and Van Camp, G. (1998). Mutations in the human al pha-tectorin gene cause autosomal dominant nonsyndromic hearing impairment. Nat. Genet. 19: 60-62.

Wagner, V., Rudi, J ., Naher, H., and Stremmel, W. (2000). Seropositivity for MIA and S100 in patients with gastrointestinal carcinomas. Med. Oncol. 17: 35-38.

Wickens, M. (1990). How the messenger got its tail: Addition of poly(A) in the nucleus. Trends. Biochem. Sci. 15: 277-281.

Wilkinson, D. G. (1992). "In Situ Hybridization: A Practical Approach," Oxford Univ. Press, Oxford.

Xie, W.-F., Kondo, S., and Sandell, L. J . (1998). Regulation of the mouse cartilage-derived retinoic acid-sensitive protein gene by the transcription factor AP-2. J . Biol. Chem. 273: 5026-5032.

Xie, W.-F., Zhang, X., Sakano, S., Lefebvre, V., and Sandell, L. J . (1999). Trans-activation of the mouse cartilage-derived retinoic acid-sensitive protein gene by Sox9. J . Bone Miner. Res. 14: 757763. 